\title{
Honey plus coffee versus systemic steroid in the treatment of persistent post-infectious cough: a randomised controlled trial
}

\author{
Mohammad Ali Raeessi', Jafar Aslani', *Neda Raeessi ${ }^{3}$, Homa Gharaie ${ }^{4}$, \\ Ali Akbar Karimi Zarchi ${ }^{5}$, Fereshteh Raeessi ${ }^{6}$
}

\author{
Department of Otolaryngology, Baqiyatallah University of Medical Sciences, Tehran, Iran \\ ${ }^{2}$ Department of Pulmonology, Baqiyatallah University of Medical Sciences, Tehran, Iran \\ ${ }^{3}$ Research Center of Tehran University of Medical Sciences, Tehran, Iran \\ ${ }^{4}$ Chief Expert of Natural Medicines Office in Deputy of Food and Drug, Ministry of Health and Medical Educations, Tehran, Iran \\ ${ }^{5}$ Department of Epidemiology and Biostatics, Faculty of Health, Baqiyatallah University of Medical Sciences, Tehran, Iran \\ ${ }^{6}$ Research Branch, Islamic Azad University of Pharmaceutical Science, Tehran, Iran
}

Originally received 3rd December 2012; resubmitted 13th March 2013; revised 3rd May 2013; accepted 21st May 2013; online 21st August 2013

\begin{abstract}
Background: Persistent post-infectious cough (PPC) is a cough that remains after a common cold or an upper respiratory tract infection for more than three weeks or perhaps for many months. Two of the suggested treatments for PPC are systemic steroid and honey plus coffee.

Aims: The aim of this study was to evaluate and compare scientifically the therapeutic effects of these two regimens.

Methods: : A double-blind randomised controlled trial was conducted from 2008 to 2011 at the Baqiyatallah University Hospital, Tehran, Iran. Included in the study were 97 adults who had experienced PPC for more than three weeks. Patients with other causes of chronic cough, systemic disease, or abnormal routine laboratory tests were excluded. The participants were distributed into three groups. A jamlike paste was prepared which consisted of honey plus coffee for the first group ('HC'), prednisolone for the second group (steroid, 'S'), and guaifenesin for the third group (control, ' $C$ '). The participants were told to dissolve a specified amount of their product in warm water and to drink the solution every eight hours for one week. All the participants were evaluated before treatment and one week after completion of treatment to measure the severity of their cough. The main outcome measure was the mean cough frequency before and after one week's treatment calculated by a validated visual analogue cough questionnaire score.

Results: There were 97 adult patients (55 men) enrolled in this study with a mean age of 40.1 years. The mean (+/- SD) cough scores pre- and post-treatment were: HC group 2.9 (0.3) pre-treatment and $0.2(0.5)$ post-treatment $(p<0.001)$; steroid (' $\mathrm{S}$ ') group 3.0 (0.0) pre-treatment and $2.4(0.6)$ post-treatment $(p<0.05)$; control (' $\left.C^{\prime}\right)$ group $2.8(0.4)$ pre-treatment and $2.7(0.5)$ post-treatment $(p>0.05)$. Analysis of variance showed a significant difference between the mean cough frequency before and after treatment in the $\mathrm{HC}$ group versus the $S$ group $(p<0.001)$. Honey plus coffee was found to be the most effective treatment modality for PPC.

Conclusions: A combination of honey and coffee can be used as an alternative medicine in the treatment of PPC.

(C) 2013 Primary Care Respiratory Society UK. All rights reserved.

MA Raeessi et al. Prim Care Respir J 2013; 22(3): 325-330

http://dx.doi.org/10.4104/pcrj.2013.00072
\end{abstract}

Keywords persistent post-infectious cough, systemic steroid, honey, coffee, randomised controlled trial

The full version of this paper, with online appendices,

is available online at www.thepcrj.org

\section{Introduction}

Cough is a common symptom of upper respiratory tract infection
(URTI). ${ }^{1}$ Generally, the cough reflex is triggered by mechanical or chemical stimulation of sensory nerve receptors which are mainly present in the pharynx, larynx, trachea, and bronchi. ${ }^{2}$ According to one theory, the main cause of cough is hypersensitivity which can be provoked by many factors. ${ }^{3,4}$

\footnotetext{
* Corresponding author: Dr Neda Raeessi, Research Center of Tehran University of Medical Sciences, No 117 Mollasadra Buildings, Kharazmi St, Mollasadra Ave, Tehran, Iran 1435913118. Tel: +98 9125839826 Fax: +98 2166405568 E-mail: raeessi_neda@yahoo.com
} 
Persistent post-infectious cough (PPC) is a cough that remains after a common cold or URTI., ${ }^{5,6}$ This cough, which is expected to last for only one or two weeks, persists for longer than three weeks or perhaps for many months. ${ }^{7}$ PPC is reported to account for $11-25 \%$ of all cases of chronic cough. ${ }^{8}$ Patients with PPC complain of a persistent tickling or irritating sensation in the throat which often leads to paroxysms of coughing. ${ }^{8}$ Even though PPC is not associated with disability and mortality, it can cause morbidity and result in medical costs. Because PPC does not cause severe debilitation and does not interfere with usual living, some people ignore it and do not get referred to clinics. However, most educated people and those with especially meticulous jobs who suffer this condition seek medical help. Such patients are frequently referred to cough clinics and are investigated for other causes of chronic cough. Therefore, PPC can be a troublesome problem for patients and physicians alike. $^{5,9}$

A specific infectious aetiology of PPC is rarely confirmed. ${ }^{10}$ Respiratory viruses - particularly respiratory syncytial virus, adenoviruses, parainfluenza, and influenza - have all been implicated. ${ }^{5,6}$ The pathogenesis of PPC is probably long-lasting and involves widespread pharyngeal mucosal inflammation, desquamation of the epithelial cells, and damage to the nerve endings that leads to hyperactivity of the cough reflex. ${ }^{8,10,11}$ These can make the pharynx more sensitive to local irritants and can lead to a vicious cycle with more damage to the mucosa. . $^{812}$ In addition, PPC is stimulated by cigarette smoke, chemical fumes, aerosol sprays, dust, perfumes, drinking, eating, talking, laughing, and breathing cold air. ${ }^{8}$

The successful treatment of PPC depends on making an accurate diagnosis. This chronic cough is usually intractable and has no remarkable response to treatment. Currently available treatments for PPC are antihistamines, narcotics, centrally acting antitussive agents such as codeine and dextromethorphan, ${ }^{6,9}$ inhaled or systemic corticosteroids, 5,6,10 inhaled ipratropium bromide, bronchodilators, cromoglycate, ${ }^{5,6}$ and the combination of honey with coffee. ${ }^{13}$

Honey is one of the oldest known medicines and has been regarded as a health-giving substance since ancient times. Its medical use is recorded from around 3000 BC onwards and it is addressed in the Holy Bible and other holy books. Honey has been valued highly in the Middle East and was mentioned as a curative substance for human illnesses in the Holy Quran 1400 years ago. In traditional medicine, honey is used to relieve the signs and symptoms of URTI and respiratory disorders, especially coughing., ${ }^{1,14-17}$ The World Health Organization (WHO) has cited honey as a potential treatment for cough and other URTI symptoms. ${ }^{14}$ It also suggests that honey demulcents may soothe the throat. ${ }^{14}$ Honey can be effective and is therefore recommended to provide some relief from cold symptoms and cough. ${ }^{14}$

Honey is produced from flower nectar by honey bees. ${ }^{18}$ It is delicious and has been reported to contain more than 200 substances such as sugars (fructose, glucose, maltose and sucrose), minerals, proteins, some vitamins, organic acids, and antioxidants (phenolic compounds, flavonoids, enzymes, carotenoid-like substances, amino acids, and other phytochemicals). ${ }^{18-20}$ By its antioxidants, honey can increase cytokine release and has antimicrobial effects. ${ }^{21-23}$ It can also prevent cellular oxidative damage that leads to ageing, disease, and death. ${ }^{18}$

Honey has been rediscovered in modern times for the maintenance of health in several diseases, ${ }^{14,24}$ burns, injuries, and wounds. It has many medicinal properties including its wound healing capacity. ${ }^{25}$ Honey reduces inflammation, oedema, and stimulates epithelialisation stages, tissue regeneration, and improvement of granulation and debridement ${ }^{1,26,27}$ which, in turn, accelerates tissue repair and leads to wound healing. ${ }^{1,17,26-30}$ Honey is also recommended in dental hygiene as it has therapeutic properties in the treatment of gingivitis and periodontal disorders. ${ }^{31,32}$ Because of its sweetness, honey reflexively stimulates saliva secretion and secretion of mucus in the airways. ${ }^{1,26,33}$ These effects may be associated with its hyperosmolarity and its anti-inflammatory and antioxidant properties. . $^{14,34,35}$

On the other hand, caffeine is a naturally occurring alkaloid found in coffee, tea, cola drinks, and cocoa. ${ }^{36}$ Methylxanthines (such as theophylline and caffeine) are bronchodilator drugs which are believed to stimulate breathing and have been used to prevent apnoea. ${ }^{36,37}$ Caffeine is also hypoalgesic and has anti-inflammatory effects. ${ }^{36,37}$ It is the world's most commonly consumed psychoactive substance that stimulates the central nervous system. ${ }^{38}$ Caffeine improves vigilance and psychomotor performance and increases levels of self-reported alertness and decreases levels of self-reported fatigue and sleepiness.

To the best of our knowledge, there has only been one previous report (from our group) on the combination of honey and coffee as a treatment for PPC. ${ }^{13}$ Considering the great number of people around the world suffering from PPC, this study was carried out to evaluate and compare the therapeutic effects of honey plus coffee with those of systemic steroids in the treatment of patients with PPC.

\section{Methods}

\section{Design and setting}

A double-blind randomised controlled trial of 97 adult patients (55 men) presenting with PPC was performed during a period of almost three years at the Baqiyatallah University Hospital, Tehran, Iran from 2008 to 2011.

\section{Participants}

The patients were assessed in our cough clinic and were registered after completion of a check list of personal data including age, sex, weight, education, occupation, duration of illness, and the presence or absence of any systemic disease. All the participants provided a comprehensive history and underwent a physical examination of the respiratory system, ear, nose, and throat. They were thoroughly examined for any abnormality and also underlying causes of their cough. In addition, routine laboratory tests were carried out and a chest $\mathrm{x}$-ray was taken. Other evaluations such as spirometry, computed tomography (CT scan) of the paranasal sinuses, and highresolution computed tomography of the thorax were carried out as necessary. 
Patients with PPC lasting more than three weeks were included in the study. Smokers and those with systemic disease and/or abnormal routine laboratory tests were excluded. A large majority of patients have more than one cause for chronic cough..$^{5,39-42}$ In this study we excluded every patient with other causes of cough or we first treated the other conditions.

In patients with chronic cough there is a positive relationship between cough frequency and cough reflex sensitivity. ${ }^{43}$ In PPC the severity of the cough is often mild to moderate but the repetition makes it annoying, and the major factor that shows it is subsiding is the reduction in its frequency. We can therefore assume that the frequency of cough is equal to the severity of cough in PPC. ${ }^{13}$ Considering the abovementioned points, we therefore consider that 'frequency of cough' represents 'severity of cough' in this study.

\section{Ethical considerations}

The participants were all volunteers and they were fully informed about the aim of the study, the potential benefits of this research, the prescribed regimens, the follow-up sessions, and their own duty as participants. They were also informed about the potential complications such as dyspepsia and insomnia, and how to face them. They were reassured that the data and their files were kept confidential. Informed consent was taken from them before they were enrolled in the study. The project design of this prospective study was approved by the Ethics Committee of the Baqiyatallah University of Medical Sciences according to the Declaration of Helsinki. This trial was registered in the Iranian Registry of Clinical Trials (IRCT: 201103034737N2).

\section{Intervention}

The included participants were randomly distributed into three groups. Three regimens of medical jam-like pastes were prepared, as follows:

(1) Each $600 \mathrm{~g}$ of the first regimen consisted of $500 \mathrm{~g}$ of honey and $70 \mathrm{~g}$ of original instant coffee, given to every member of the first group (honey plus coffee group, $\mathrm{n}=29$ )

(2) Each $600 \mathrm{~g}$ of the second regimen consisted of $320 \mathrm{mg}$ prednisolone given to every member of the second group (steroid group, $n=30$ ).

(3) Each $600 \mathrm{~g}$ of the third regimen consisted of only guaifenesin as a supportive treatment given to every member of the third group (control/placebo group, $\mathrm{n}=26$ ).

All three products were similar in packaging, colour, shape, and taste (by adding enough edible brown colour, coffee essence, artificial honey flavour, and liquid glucose). The dosages of the ingredients were determined according to usual daily usage. The ingredients of each product were gently mixed and homogenised. These products should be kept at room temperature of about $22-26^{\circ} \mathrm{C}$. The natural honey used in this study was obtained from the region of the Zagros Mountains in the west of Iran and the coffee was original instant coffee produced in Spain by Nestle Spain Ltd.

The samples were produced by our pharmacists. The sample sizes were determined using a computerised randomised programme and they were encoded confidentially and distributed randomly between the participants. The participants were told to dissolve one tablespoon (about $25 \mathrm{~g}$ ) of the prescribed jam-like paste

\section{Table 1. Characteristics of participants}

\begin{tabular}{llll} 
Factors & $\begin{array}{l}\text { HC group } \\
(\mathrm{n}=29)\end{array}$ & $\begin{array}{l}\text { S group } \\
(\mathrm{n}=30)\end{array}$ & $\begin{array}{c}\text { C group } \\
(\mathrm{n}=26)\end{array}$ \\
\hline $\begin{array}{l}\text { Age groups } \\
\leq 30\end{array}$ & $6(21)$ & $12(40)$ & $5(19)$ \\
$31-40$ & $7(24)$ & $8(27)$ & $6(23)$ \\
$41-50$ & $8(28)$ & $6(20)$ & $9(31)$ \\
$51-60$ & $7(24)$ & $4(13)$ & $6(23)$ \\
$\geq 61$ & $1(3)$ & $0(0)$ & $0(0)$ \\
\hline Sex & & & \\
$\quad$ Male & $18(62)$ & $20(67)$ & $13(50)$ \\
Female & $11(38)$ & $10(33)$ & $13(50)$ \\
\hline Level of schooling & & & \\
$\quad$ Primary \& Diploma & $7(24)$ & $12(40)$ & $6(23)$ \\
$\quad \begin{array}{l}\text { Technical \& Higher } \\
\text { education }\end{array}$ & $19(65)$ & $13(43)$ & $20(77)$ \\
\hline $\begin{array}{l}\text { Occupation } \\
\text { Housewife }\end{array}$ & $8(28)$ & $5(17)$ & $7(27)$ \\
Student and employee & $2(41)$ & $13(43)$ & $9(31)$ \\
Physician & $6(21)$ & $9(30)$ & $9(31)$ \\
\hline
\end{tabular}

Data are presented as $n(\%)$ within each treatment group.

$\mathrm{C}=$ control, $\mathrm{HC}=$ honey plus coffee, $\mathrm{S}=$ steroid.

in one glass (about $200 \mathrm{~mL}$ ) of warm water $\left(<60^{\circ} \mathrm{C}\right.$ ) and then to drink the solution. They were asked to repeat it every eight hours for one week. There were therefore 24 doses in each $600 \mathrm{~g}$ of jam-like paste, and the doses for each group were approximately:

1) HC group: $20.8 \mathrm{~g}$ of honey and $2.9 \mathrm{~g}$ of coffee three times daily

2) Steroid group: $13.3 \mathrm{mg}$ of prednisolone three times daily

3) Control group: $25 \mathrm{~g}$ of guaifenesin three times daily

The participants were told about all three prescriptions but they were unaware of their own regimen. They agreed not to use any additional anti-inflammatory and antitussive agents, even honey or coffee.

\section{Main outcome measures}

In all participants the frequency of their cough was evaluated before treatment and one week after completion of treatment and the check lists were completed. We chose one week after the completion of treatment in order to evaluate only the lasting effects of the regimens and to eliminate their sedative effects. In addition, the participants were kept under observation for the first month even if their cough was cured. A cough questionnaire was designed (see Appendix 1, available online at www.thepcrj.org) and its validity was accepted by five experts in the field. With regard to reliability, the questionnaire had a Cronbach's alpha coefficient of 0.908. The questionnaires were completed by physicians according to patients' answers using a visual analogue score and the participants were then categorised on the basis of a Likert-type scale graded as nothing (0), low (1+), moderate (2+), and high (3+). ${ }^{1.44}$ The study investigators who checked patients' signs and symptoms were unaware of the prescribed regimen and none of them participated 


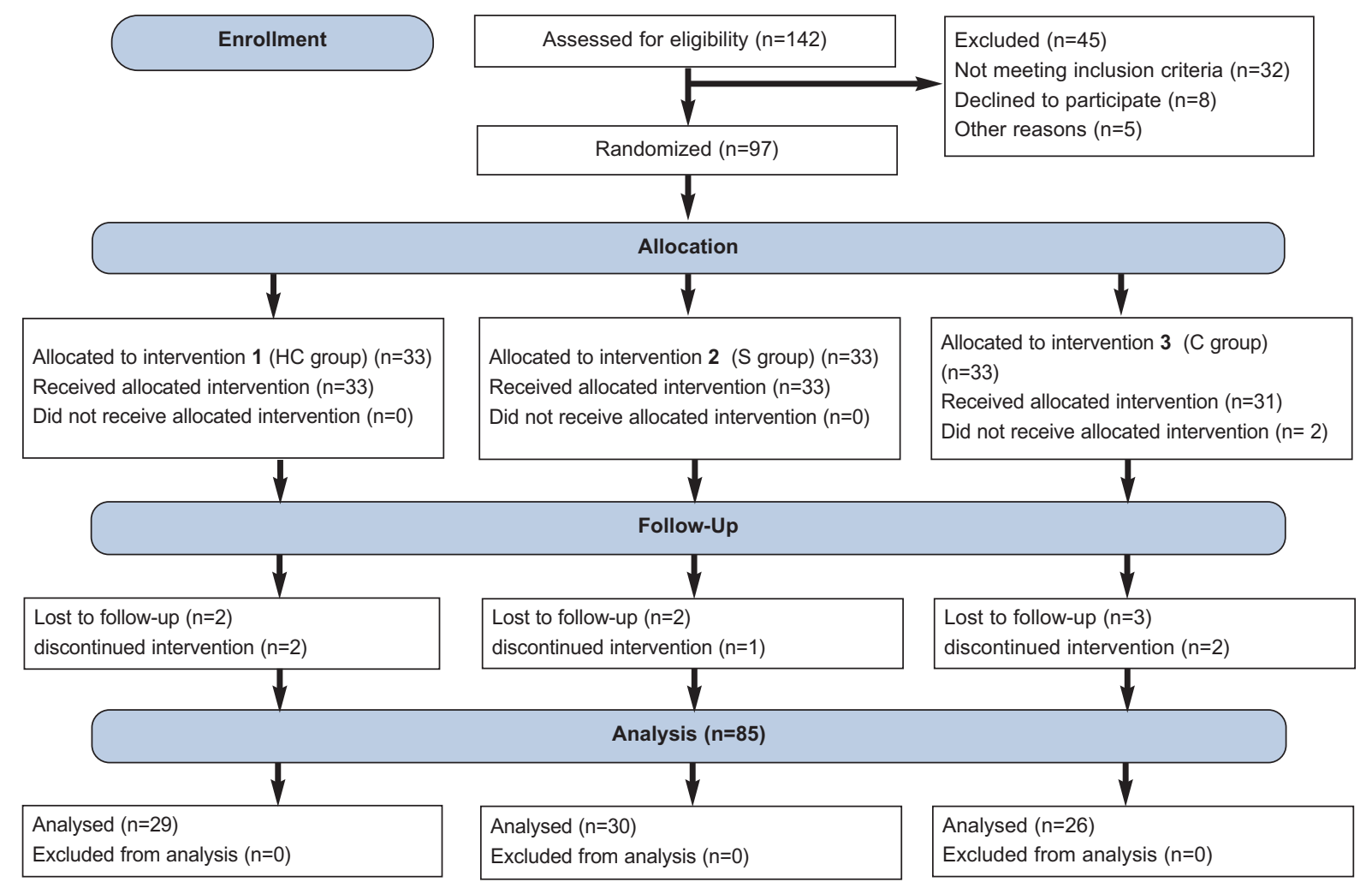

as patients in the study. The process of this research is illustrated by the flow diagram in Figure 1, and the completed CONSORT checklist is Appendix 2 the attached (available online at www.thepcrj.org).

\section{Statistical analysis}

All the analyses were carried out using SPSS V.15.0 software. Continuous variables were presented as mean (standard deviation, $\mathrm{SD}$ ) and categorical variables were presented as absolute and relative frequencies. One-way ANOVA, $\chi^{2}$ test, Wilcoxon signed ranks test, and paired t tests were used to compare the groups. All reported $p$ values were based on two-sided hypotheses. The distribution of the baseline data is shown in Table 1.

\begin{tabular}{|c|c|c|c|c|}
\hline Variables & HC group & $S$ group & C group & $\mathrm{p}$ Value \\
\hline Age (years): & $42.3(13.2)$ & $36.1(11.9)$ & $42.0(11.8)$ & 0.103 (NS) \\
\hline Weight (kg): & $76.1(12.9)$ & $77.1(8.8)$ & $73.9(9.9)$ & 0.534 (NS) \\
\hline $\begin{array}{l}\text { Duration of illness } \\
\text { (months): }\end{array}$ & $3.0(2.9)$ & $2.9(1.5)$ & $2.9(2.7)$ & 0.973 (NS) \\
\hline \multicolumn{5}{|c|}{ Frequency of cough (degree): } \\
\hline Before treatment & $2.9(0.3)$ & $3.0(0.0)$ & $2.8(0.4)$ & 0.082 (NS) \\
\hline After treatment & $0.2(0.5)$ & $2.4(0.6)$ & $2.7(0.5)$ & $<0.001(\mathrm{~S})$ \\
\hline
\end{tabular}

$\mathrm{C}=$ control, HC=honey plus coffee, $\mathrm{S}=$ steroid, $(\mathrm{NS})=$ not significant, $(\mathrm{S})=$ significant.

\section{Results}

In this clinical trial the mean (SD) of age, weight and duration of illness were 40.1 (12.5) years, 75.8 (10.6) kg, and 2.9 (2.4) months, respectively. Participants' ages ranged from 21 to 65 years. Their weight ranged from $50 \mathrm{~kg}$ to $90 \mathrm{~kg}$ and most were highly educated (Table 1). The mean (SD) frequency of cough before and after the treatment were $2.94(0.23)$ and 1.71 (1.22), respectively (Table 2).

The difference between variables including age, duration of illness in months and frequency of cough before treatment in all three groups were similar and were not statistically significant ( $p>0.05$, Table 2). The $\chi^{2}$ test showed that the distribution of variables including sex, education, and occupation was the same in the three groups ( $p>0.05)$.

According to the Wilcoxon signed rank test, the cough frequency was similar in all three groups before treatment ( $p>0.05$ ). Changes in the frequency of cough in the honey plus coffee and steroid groups after treatment were significant $(p<0.05)$ but were not significant in the control group ( $p>0.05)$. Thus, the steroid and honey plus coffee regimens were effective in treating the condition. Analysis of variances showed that the difference between the mean cough frequency before and after treatment with the steroid and honey plus coffee regimens was significant $(p<0.001)$.

In addition, post hoc Tukey tests showed that changes in cough frequency before and after treatment in the steroid and control groups were not significant ( $p>0.05$ ) while the mean change in 
cough frequency before and after treatment in the honey plus coffee group was higher than in the other two groups and was statistically significant $(p<0.001)$. The results of this study show that the honey plus coffee regimen had a significantly more curative effect on cough frequency than the other two regimens.

\section{Discussion}

\section{Main findings}

The aim of the present study was to evaluate and compare the therapeutic effects of honey plus coffee with systemic steroid and with control/placebo agents in patients with PPC. The results show that, compared with systemic steroid, the combination of honey and coffee is a better treatment modality for PPC. The treatment is safe and effective and also eliminates the unpleasant consequences of illness for both patients and physicians. These are interesting findings. Interpretation of findings in relation to previously published work

Each year, billions of dollars are spent on controlling and trying to cure cough while the real effect of cough medicines is not quite reliable. ${ }^{1.45}$ Even though PPC is reported to account for only $11-25 \%$ of all cases of chronic cough ${ }^{8}$ and it is not associated with disability and mortality, it can cause morbidity and is responsible for medical costs..$^{13}$

The exact mechanism of action of honey is not definitely known but acidity, osmolality, and hydrogen peroxide production have been proposed to be important factors. ${ }^{17}$ Honey lowers plasma prostaglandin concentrations by reducing prostaglandin synthesis at the site of application. ${ }^{23}$ It also increases nitric oxide (NO) levels in the lesions and has antioxidant and anti-inflammatory activities. ${ }^{23}$ It seems to be that, due to their hyperosmolarity, sweet substances naturally stimulate the salivation reflex and thereby the hypersecretion of airway mucus. These can improve mucociliary clearance in the airway and lead to a demulcent effect in the pharynx resulting in reduced cough. ${ }^{1,14,26,33,39}$ These effects may be associated with the hyperosmolarity and anti-inflammatory and antioxidant properties of honey. ${ }^{14,34,35}$ As a result of these properties, honey can expedite the repair and healing of pharyngeal mucosal desquamation and therefore reduce mucosal irritation. ${ }^{1,14,24,26,33-35,39}$

We chose the combination of honey and coffee because both are mentioned as cough remedies in complementary medicine and their combination is acceptable and safe. Although honey and coffee separately have been reported to have treatment effects on some respiratory diseases and they can induce mucosal tissue healing, to the best of our knowledge there is no report in the literature on the combination of these two except our previous study of the efficacy of honey plus coffee in the treatment of PPC. ${ }^{13}$ That study showed that honey plus coffee is the most effective treatment modality for PPC, and also that the effect of the combination is greater than the effect of each one separately. ${ }^{13}$

The exact mechanism of action of the combination of honey and coffee is unknown and has not been fully explained, but may be due to the synergistic effect of these two substances. This combination can bring about notable improvements in mucosal tissue healing by repairing the nerve ending damage caused by mucosal desquamation and mucosal irritability. This may provide a possible explanation for the role of honey and coffee in the successful treatment of PPC.

Honey and coffee are natural edible substances that are safe, agreeable, less expensive than medicines, and easily available. Moreover, they have proved to be effective in a short period of time. Strengths and limitations of this study

This study was carried out in accordance with our previous study ${ }^{13}$ and its principles and with the addition of a control/placebo group. The addition of guaifenesin in the control group was intended to have some medical effects for participants in the third group and not to deprive them of medical treatment. In order to obtain the best effect of prednisolone we chose an approximate dosage of 40$45 \mathrm{mg}$ daily, which is the maximum suggested dosage for the treatment of PPC. It is important to point out that the total amount of our products used by the participants in the one-week treatment period was constant and small deviations in the daily dosage do not make much difference.

Implications for future research, policy and practice

Further investigations in this field with larger sample sizes will make the results more reliable and we hope to see such studies in other settings in the future.

\section{Conclusions}

PPC may be successfully treated by a combination of honey and coffee in a short time. Compared with systemic steroid, this treatment modality can be used as an alternative medicine in the treatment of PPC. We therefore recommend the use of this effective treatment modality for PPC patients. Further investigations are warranted.

\section{Handling editor Gopal Netuveli Statistical review Gopal Netuveli}

Acknowledgements We would like to thank all the people who helped us in this research project, especially Professor Shahin Akhondzadeh for his editing of the manuscript.

Conflicts of interest The authors declare that they have no conflicts of interest in relation to this article.

Contributorship MAR designed the research project, carried out clinical evaluations, supervised the whole study group and drafted the manuscript. JA participated in study design and clinical evaluations. NR participated in clinical evaluations, drafting the manuscript and reviewed it. She is the corresponding author. HG participated in study design, was responsible for the all pharmaceutical work and prepared and identified various samples. AAKZ was the statistical and epidemiological advisor and calculated the sample size, interpreted the collected data, and did the statistical analysis. FR participated in clinical evaluations, producing the samples and drafting the manuscript. All the authors have read and approved the manuscript before submission.

Funding All the costs were covered by Baqiyatallah University of Medical Sciences and the authors personally.

Trial registration: Current Controlled Trials IRCT 201103034737N2.

\section{References}

1. Shadkam MN, Mozaffari-Khosravi H, Mozayan MR. A comparison of the effect of honey, dextromethorphan, and diphenhydramine on nightly cough and sleep quality in children and their parents. J Altern Complement Med 2010;16(7):787-93. http://dx.doi.org/10.1089/acm.2009.0311

2. McGarvey LP. Idiopathic chronic cough: a real disease or a failure of diagnosis? Cough 2005;1:9. http://dx.doi.org/10.1186/1745-9974-1-9

3. Kaplan A. A 54 year-old man with a chronic cough: a primary care perspective from 
Canada. Prim Care Respir J 2012;21(3):342-3.

http://dx.doi.org/10.4104/pcri.2012.00075

4. Ponsion BP, Hop WCJ, Vermue NA, Bohnen AM. Characteristics of adults with persistent cough in general practice. Prim Care Respir J 2002;11(2):69.

5. Irwin RS, Baumann MH, Bolser DC, et al. Diagnosis and management of cough executive summary: ACCP evidence-based clinical practice guidelines. Chest 2006;129(1 Suppl):1S-23S. http://dx.doi.org/10.1378/chest.129.1.1

6. Braman SS. Postinfectious cough: ACCP evidence-based clinical practice guidelines. Chest 2006;129(1 Suppl):138S-46S

http://dx.doi.org/10.1378/chest.129.1_suppl.138S

7. Zimmerman B, Silverman FS, Tarlo SM, Chapman KR, Kubay JM, Urch B. Induced sputum: comparison of postinfectious cough with allergic asthma in children. $J$ Allergy Clin Immunol 2000;105(3):495-9. http://dx.doi.org/10.1067/mai.2000.104933

8. Chung KF, Pavord ID. Prevalence, pathogenesis, and causes of chronic cough. Lancet 2008;371(9621):1364-74. http://dx.doi.org/10.1016/50140-6736(08)60595-4

9. Morice AH, McGarvey L, Pavord I, British Thoracic Society Cough Guideline Committee. Recommendations for the management of cough in adults. Thorax 2006;61(Suppl 1):i1-24. http://dx.doi.org/10.1136/thx.2006.065144

10. Ryan NM, Gibson PG. Extrathoracic airway hyperresponsiveness as a mechanism of post infectious cough: case report. Cough 2008;4:7. http://dx.doi.org/10.1186/1745-9974-4-7

11. Saleh H. Rhinosinusitis, laryngopharyngeal reflux and cough: an ENT viewpoint. Pulm Pharmacol Ther 2009;22(2):127-9. http://dx.doi.org/10.1016/j.pupt.2009.01.002

12. Pavord ID, Chung KF. Management of chronic cough. Lancet 2008;371(9621):1375-84. http://dx.doi.org/10.1016/s0140-6736(08)60596-6

13. Raeessi MA, Aslani J, Gharaie H, Karimi Zarchi AA, Raeessi N, Assari Sh. Honey with coffee: a new finding in the treatment of persistent postinfectious cough. Iran J OtoRhino-Laryng 2011;23(2):1-8

14. Paul IM, Beiler J, McMonagle A, Shaffer ML, Duda L, Berlin CM Jr. Effect of honey, dextromethorphan, and no treatment on nocturnal cough and sleep quality for coughing children and their parents. Arch Pediatr Adolesc Med 2007;161(12):1140-6. http://dx.doi.org/10.1001/archpedi.161.12.1140

15. Pfeiffer WF. A multicultural approach to the patient who has a common cold. Pediatr Rev 2005;26(5):170-5. http://dx.doi.org/10.1542/pir.26-5-170

16. Haq F, Ahmad H, Alam M. Traditional uses of medicinal plants of Nandiar Khuwarr catchment (District Battagram),Pakistan. J Med Plant Res 2011;5(1):39-48

17. Al-Waili NS. Topical application of natural honey, beeswax and olive oil mixture for atopic dermatitis or psoriasis: partially controlled, single-blinded study. Complement Ther Med 2003;11(4):226-34. http://dx. doi.org/10.1016/50965-2299(03)00120-1

18. Yao LK, Abdul Razak SL, Ismail N, et al. Malaysian gelam honey reduces oxidative damage and modulates antioxidant enzyme activities in young and middle aged rats. J Med Plant Res 2011;5(23):5618-25.

19. Zaid SS, Sulaiman SA, Sirajudeen KN, Othman NH. The effects of Tualang honey on female reproductive organs, tibia bone and hormonal profile in ovariectomised rats: animal model for menopause. BMC Complement Altern Med 2010;10:82. http://dx.doi.org/10.1186/1472-6882-10-82

20. Makpol S, Tengku Ahmad TAF, Jubri Z, Rejab N, Yusof N, Yusof YAM. Gelam honey acting as a radioprotectant agent in gamma-irradiated human diploid fibroblasts. $J$ Med Plant Res 2012;6(1):129-38.

21. Tan HT, Rahman RA, Gan SH, et al. The antibacterial properties of Malaysian tualang honey against wound and enteric microorganisms in comparison to manuka honey. BMC Complement Altern Med 2009;9:34. http://dx.doi.org/10.1186/1472-6882-9-34

22. Basson NJ, Grobler SR. Antimicrobial activity of two South African honeys produced from indigenous Leucospermum cordifolium and Erica species on selected microorganisms. BMC Complement Altern Med 2008;8:41 http://dx.doi.org/10.1186/1472-6882-8-41

23. Al-Waili NS. An alternative treatment for pityriasis versicolor, tinea cruris, tinea corporis and tinea faciei with topical application of honey, olive oil and beeswax mixture: an open pilot study. Complement Ther Med 2004;12(1):45-7. http://dx.doi.org/10.1016/j.ctim.2004.01.002

24. Bogdanov S, Jurendic T, Sieber R, Gallmann P. Honey for nutrition and health: a review. J Am Coll Nutr 2008:27(6):677-89. http://dx.doi.org/10.1080/07315724.2008.10719745

25. Al Ameen NM, Altubaigy F, Jahangir T, Mahday IA, Mohammed EA, Musa OA. Effect of Nigella sativa and bee honey on pulmonary, hepatic and renal function in Sudanese in Khartoum state. J Med Plant Res 2011;5(31):6857-63.

26. Nilforoushzadeh MA, Jaffary F, Moradi S, Derakhshan R, Haftbaradaran E. Effect of topical honey application along with intralesional injection of glucantime in the treatment of cutaneous leishmaniasis. BMC Complement Altern Med 2007;7:13. http://dx.doi.org/10.1186/1472-6882-7-13

27. Khoo YT, Halim AS, Singh KK, Mohamad NA. Wound contraction effects and antibacterial properties of Tualang honey on full-thickness burn wounds in rats in comparison to hydrofibre. BMC Complement Altern Med 2010;10:48. http://dx.doi.org/10.1186/1472-6882-10-48

28. Molan PC. Potential of honey in the treatment of wounds and burns. Am J Clin Dermatol 2001;2(1):13-19. http://dx.doi.org/10.2165/00128071-200102010-00003

29. Sherlock $O$, Dolan A, Athman R, et al. Comparison of the antimicrobial activity of Ulmo honey from Chile and Manuka honey against methicillin-resistant Staphylococcus aureus, Escherichia coli and Pseudomonas aeruginosa. BMC Complement Altern Med 2010;10:47. http://dx.doi.org/10.1186/1472-6882-10-47

30. Nasir NA, Halim AS, Singh KK, Dorai AA, Haneef MN. Antibacterial properties of tualang honey and its effect in burn wound management: a comparative study. BMC Complement Altern Med 2010;10:31. http://dx.doi.org/10.1186/1472-6882-10-31

31. Pipicelli G, Tatti P. Therapeutic properties of honey. Health 2009;1(2):281-3. http://dx.doi.org/10.4236/health.2009.14045

32. English HK, Pack AR, Molan PC. The effects of manuka honey on plaque and gingivitis: a pilot study. J Int Acad Periodontol 2004;6(2):63-7.

33. Eccles R. Mechanisms of the placebo effect of sweet cough syrups. Respir Physiol Neurobio/ 2006;152(3):340-8. http://dx.doi.org/10.1016/j.resp.2005.10.004

34. Moore OA, Smith LA, Campbell F, Seers K, McQuay HJ, Moore RA. Systematic review of the use of honey as a wound dressing. BMC Complement Altern Med 2001;1:2. http://dx. doi.org/10.1186/1472-6882-1-2

35. Ghashm AA, Othman NH, Khattak MN, Ismail NM, Saini R. Antiproliferative effect of Tualang honey on oral squamous cell carcinoma and osteosarcoma cell lines. $B M C$ Complement Altern Med 2010;10:49.

36. Welsh EJ, Bara A, Barley E, Cates CJ. Caffeine for asthma. Cochrane Database Syst Rev 2010;(1):CD001112.

37. Henderson-Smart DJ, Steer PA. Caffeine versus theophylline for apnea in preterm infants. Cochrane Database Syst Rev 2010;(1):CD000273.

38. Davis JK, Green JM. Caffeine and anaerobic performance: ergogenic value and mechanisms of action. Sports Med 2009;39(10):813-32 http://dx.doi.org/10.2165/11317770-0000000000-00000

39. McGarvey LP, Ing AJ. Idiopathic cough, prevalence and underlying mechanisms. Pulm Pharmacol Ther 2004;17(6):435-9. http://dx.doi.org/10.1016/j.pupt.2004.09.012

40. Tasca R. Chronic cough. Clin Otolaryngo/ 2008;33(6):630. http://dx.doi.org/10.1111/j.1749-4486.2008.01760.x

41. Cathcart RA, Steen N, Natesh BG, Ali KH, Wilson JA. Non-voice-related throat symptoms: comparative analysis of laryngopharyngeal reflux and globus pharyngeus scales. J Laryngol Otol 2011;125(1):59-64 http://dx.doi.org/10.1017/S0022215110001866

42. Ghanei M, Hosseini AR, Arabbaferani Z, Shahkarami E. Evaluation of chronic cough in chemical chronic bronchitis patients. Environ Toxicol Pharmacol 2005;20(1):610. http://dx.doi.org/10.1016/.etap.2004.09.006

43. Birring SS, Matos S, Patel RB, Prudon B, Evans DH, Pavord ID. Cough frequency, cough sensitivity and health status in patients with chronic cough. Respir Med 2006;100(6):1105-09. http://dx.doi.org/10.1016/..rmed.2005.09.023

44. Shohrati M, Aslani J, Eshraghi M, Alaedini F, Ghanei M. Therapeutics effect of $\mathrm{N}$ acetyl cysteine on mustard gas exposed patients: evaluating clinical aspect in patients with impaired pulmonary function test. Respir Med 2008;102(3):443-8. http://dx.doi.org/10.1016/..rmed.2007.10.004

45. Morice AH. Epidemiology of cough. Pulm Pharmacol Ther 2002;15(3):253-9. http://dx.doi.org/10.1006/pupt.2002.0352 


\section{Chronic Persistent Dry Cough Questionnaire}

No:

Name:

Age: Sex: Weight:

Date:

Education (Grade): Phone: [ Address:

Chronic Cough: $\quad$ Severe $\square \quad$ Moderate $\square$

Other Signs \& Symptoms:

Duration of chronic cough (How long persisted):

The cough stimulants are: (chemical or mechanical stimulation of the cough reflex)

Eating: $\{\square$ all - $\square$ special $\}$-- Drinking: $\{\square$ all - $\square$ special $\}$-- $\square$ Smoking

$\square$ Breathing cold air, -- $\square$ Perfume Smelling, -- $\square$ Talking, -- $\square$ Others.

How many times the patient has been referred to physician:

History of previous treatments:

History of Hyperglycemia:

History of other Disease:

Comprehensive history and Physical examination:

Chest:

Chest X Ray:

BP:

Spirometry:

RR: $\square$ PR: $\square$

As necessary (PNS CT scan, HRCT, MRI, Routine laboratory tests, ...):

\section{Which common causes of chronic cough are present:}

1-URI and other respiratory infections, Sinusitis, Postnasal drip syndrome (PND):

2-Gastroesophageal reflux (GERD):

3 -Asthma, Allergy (probable atopic cough):

4-Postinfectious chronic cough:

5-Chronic bronchitis, bronchiectasis, parenchymal pulmonary diseases:

6-Respiratory tumors, respiratory tract foreign bodies:

7-Psychogenic cough:

8-Smoking:

ENT examinations: Ear: Normal

Abnormal

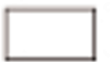

Nose: Normal

Abnormal

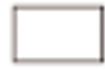

Throat: Normal

Abnormal

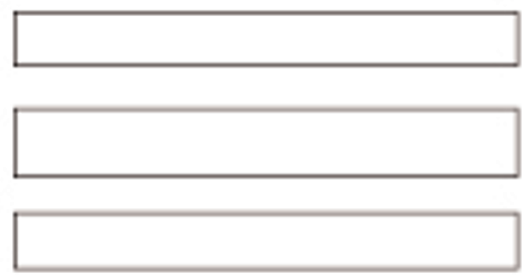


Clinical diagnosis:

Differential diagnosis:

Date: Sign:

Accepted, Excluded,

First needs other treatments,

Date: Treatment in this study by: D. No:

Sign:

Date:

Compliance: Well

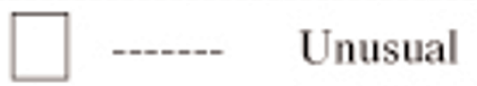

Severity of cough:

$\square+++$

$\square++\quad \square+$

$\square 0$

Sign:

As Necessary:

Date:

Compliance: Well

$\square$

$-$

Unusual

Severity of cough (2): $\square+++\quad \square++\quad \square+\quad \square 0 \quad$ Sign: 


\section{Appendix 2}

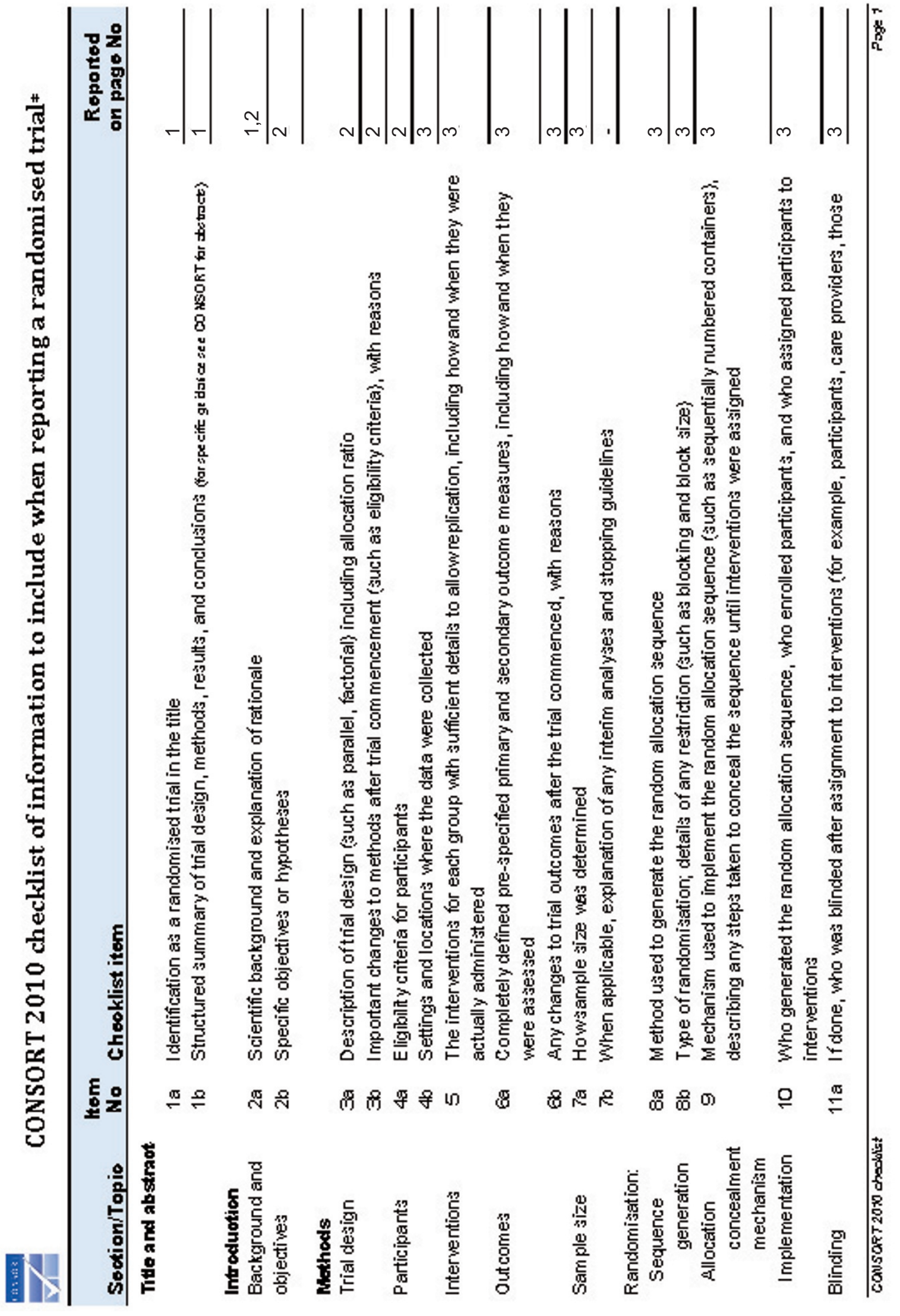




\section{Appendix 2 continued}

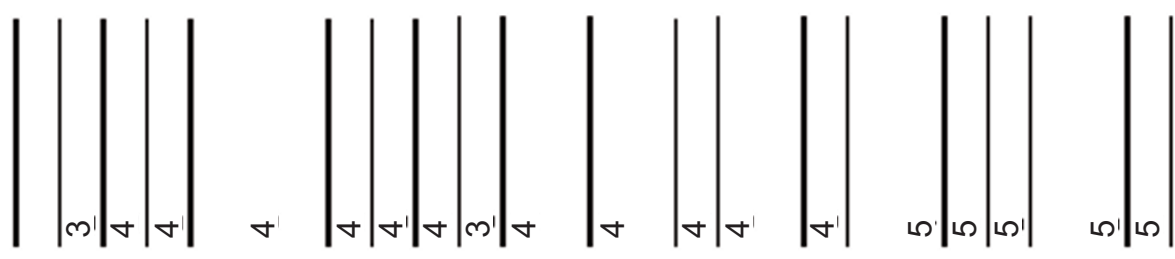
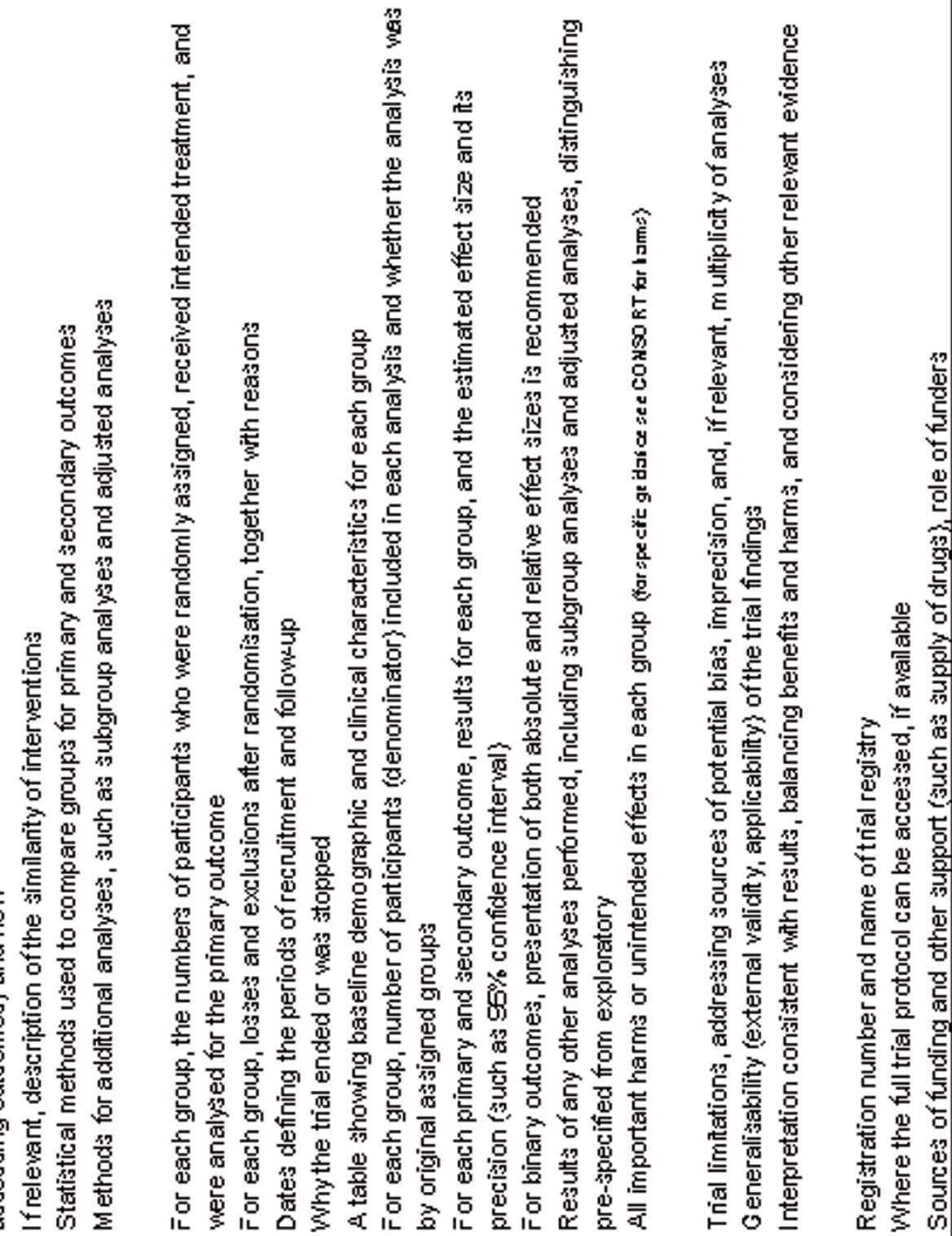

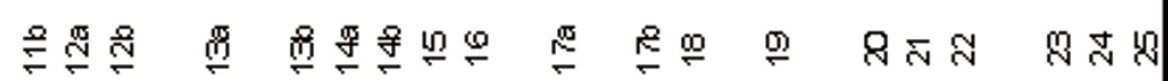
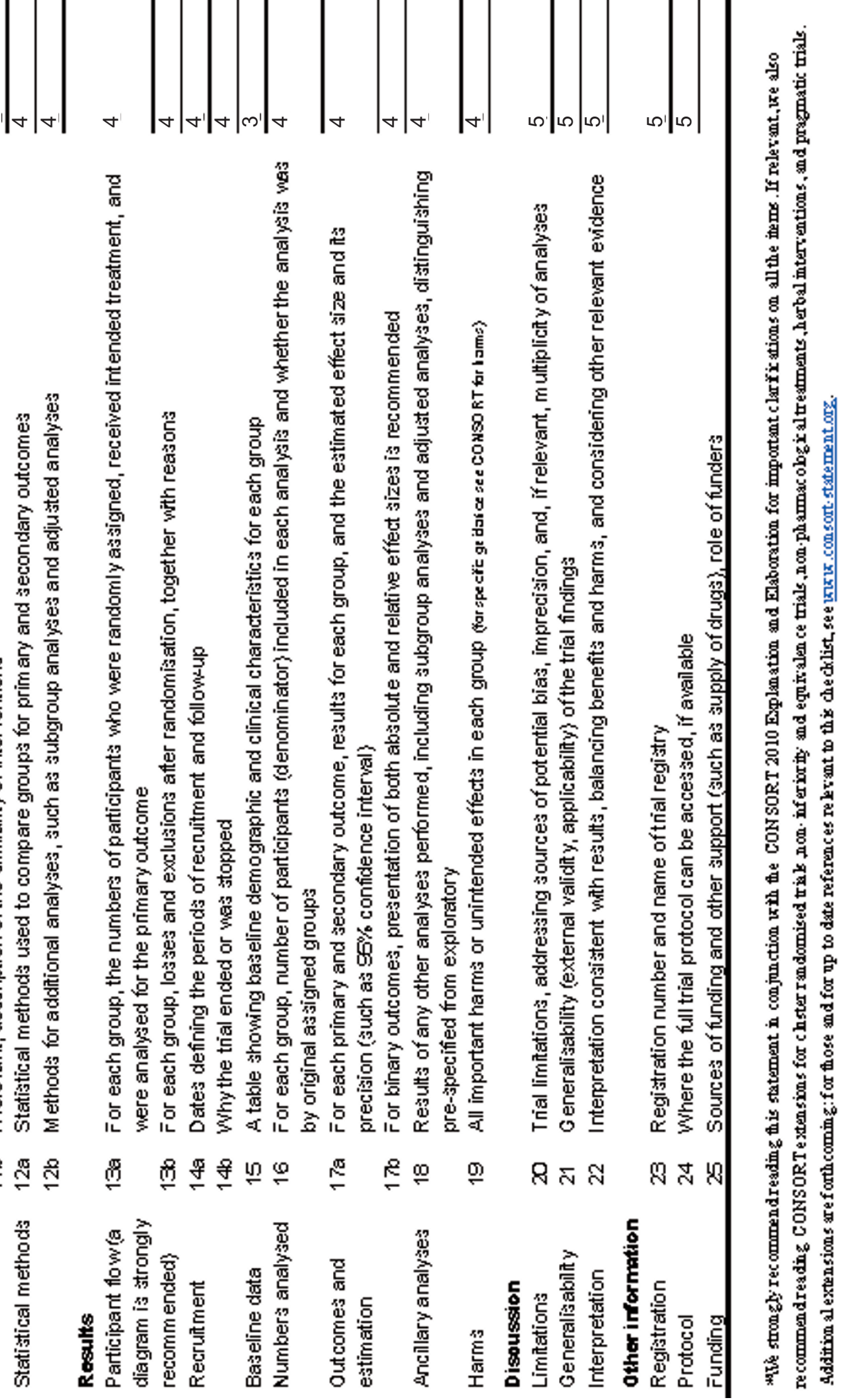